\title{
From Welfarism to Non-welfarism: Literature Review on the Evolution of Welfare Economics System
}

\author{
Ji-hong DUAN*, Wen-hui LV, Shan-shan HUANG and Xin DENG
}

School of Economics, Nanjing University of Finance \& Economics, Nanjing, Jiangsu, China

${ }^{*}$ Corresponding author

Keywords: Welfare Economics; Welfarism; Non-welfarism.

\begin{abstract}
Welfare economics is an important branch of modern economics. From its birth until now, welfare economics has roughly experienced six stages: the sprout of welfare economics, the old welfare economics, the new welfare economics, the relative welfare doctrine, the expansion of welfare economics, and non-welfarism. The basic power of evolution of the welfare economics system derives from the theoretical innovation of the welfare concept. Based on previous theoretical studies, this paper discusses how welfare economics advances with the development of the academic and economic from the perspective of evolution of the welfare economics theory. The rise of non-welfarism has provided a new direction for the discussion of this issue.
\end{abstract}

\section{Introduction}

Welfare economics is a very broad subject. As long as human beings begin to study economic activities and economic phenomena, it is necessary to discuss how to evaluate these economic activities and economic phenomena.

To understand what welfare economics is, we must first understand what welfare is. Benefits are usually examined from an economic perspective, that is, economic welfare. Economic welfare is the portion of social welfare that can be measured directly or indirectly in money. As the theory evolves, the concept of welfare generally has the following explanations. Utilitarian welfare theory holds that personal welfare, ie personal utility, refers to the satisfaction that a person gains. It can be seen as a synonym for "happiness", "happy", "desire to be satisfied" or "maximizing choice behavior". This satisfaction includes both the satisfaction of personal material life needs and the satisfaction of personal spiritual life needs; the objectivist welfare theory holds that personal welfare should be examined from the income, wealth, possession of goods or consumption expenditures, and the possession of basic goods or resources; Amartya Sen believed that personal welfare should be examined from perspective of the individual's realized functions and capabilities and freedom.

With regard to welfare economics, Western economists have various definitions. Earlier welfare economists described it as the science of studying social well-being and the economic reasons for its change. One of the representatives of welfare economics, A.C.Pigou, believed that welfare economics researches had the main influence to increase the world's or a country's economic welfare [1]. Later welfare economists mostly defined welfare economics from another perspective. The British economist, I·M·D Little, believed that "it is best to think of welfare economics as a form of studying the economic system is better or worse than another, and should a form be changed to another form?" [2] Mishan argued that "theoretical welfare economics is the branch of the discipline that ranks socially available economic conditions using better or worse standards." [3] In the Western popular textbook on welfare economics, he wrote: "Welfare economics is a framework for evaluating the importance of economic events in terms of norms..." That is, welfare economists want to determine whether a particular policy is worth - not based on his or her value, but on some clearly expressed ethical standards [4]. The Chinese-American economist Yew-Kwang, $\mathrm{Ng}$ believed that "Welfare economics is a discipline branch that studies a state that is superior or inferior to another state." [5] The above scholars have defined welfare economics from various perspectives. In a nutshell, welfare economics is the use of social selection criteria (this standard needs to be defined) to evaluate various economic conditions based on different systems (mainly the 
government and the market) that society can choose from, and sort out social status so as to identify the optimal economic status.

\section{The Evolution Path from Welfarism to Non-welfarism}

Welfare economics is an important branch of modern economics, its development has been a long time. It was formed as an official discipline in the United Kingdom in the early 20th century and was later widely disseminated and developed in the United States, France, and the Nordic countries. Under the tradition of ethics, Western economics gradually developed. However, during the marginal revolutionary period of the $1870 \mathrm{~s}$, the development of Western economies lost the tradition of ethics and replaced it with the tradition of engineering. Until the 1920s, the old welfare economics represented by Pigou reintegrated into ethics; in the 1930s and 1940s, because of the difference in ethical foundations, the new welfare economics replaced the old welfare economics and became popular; in the 1950s and 1960s, the new welfare economics fell into a state of predicament. Since the 1970s, the welfare economics began to pay attention to the theory of fairness, equality and justice, and at the same time challenged welfarism and proposed the new direction of welfare economics - non-welfarism. From its birth until now, welfare economics has roughly experienced the six stages of the sprout of welfare economics, the old welfare economics, the new welfare economics, the relative welfare doctrine, the expansion of welfare economics, and non-welfarism.

\subsection{The sprout of welfare economics}

Benjamin Franklin once said that economists are not concerned with theory in order to care about theory, but use economic theory to solve real economic problems and promote the welfare of the entire society. Therefore, from this perspective, the germ of welfare economics has emerged from the fact that humanity has begun to pay attention to its own economic behavior. Of course, this reference to welfare economics is too general. In order to better understand the origins of welfare economics, we introduce three perspectives on welfare economics.

The first view holds that the ideological origins of welfare economics can at least be traced back to Adam Smith. Adam Smith put forward the principle of "invisible hand" in The Study of the Nature and Causes of National Wealth [6]. Adam Smith believed that the economic actions taken by every economically active person were trying to obtain their own maximum economic benefits at their own minimum economic costs. In the process of chasing one's own interests, there is an "invisible hand" that leads him to promote a goal that is the greatest of personal interests that brings social benefits. From Smith's remarks, we can draw the following three conclusions: first, the main motive of mankind is his own self-interest; second, the "invisible hand" of competition automatically turns many private interests into common interests; third, the government should less interfere with the economy. Smith's point of view was put forward based on the opposition to the mercantilist countries' interventionist view. Smithism supports laissez-faire and mercantilism advocates state intervention. Welfare economics is one of the by-products of the fundamental debate between Smithism and mercantilism. The theoretical aspect of welfare economics is built and developed around three major propositions. First, is there a result that is in the public interest in a competitive buyer and seller economy? Second, in an economic system, the distribution plan is formulated by a visionary ruler. Is the public interest obtained through a slightly changing market mechanism or is the market mechanism completely eliminated? Third, the consequences of restricting social welfare are through the market or the process of voting. From the above analysis, it can be seen that although Smith does not clearly put forward the concept of welfare, he has already begun to discuss welfare issues in his works and it is the seed of welfare economics. Of course, the idea of welfare is reflected in the works among economists such as David Ricardo, Karl Marx, JS Mill, and Alfred Marshall.

The second view is that welfare economics really originated from the founder of classical utilitarian Jeremy Bentham (1789). We know that Bentham was a scholar of the same period as Borda and Condorcet. Condorcet believed that the revolution "opens the door to hope for 
humankind" and gave a high evaluation of the American Revolutionary War and the French Revolution. On the contrary, Bentham was extremely opposed to inviolable natural rights. He pointed out: "Natural rights are nothing but nonsense". He believed that a country's welfare (happiness) should be defined as the sum of satisfaction of each citizen, and the goal of public institutions and public actions was to achieve "the greatest happiness of the greatest number of people." [7] According to Bentham's utilitarian view, the legislator's task should be to enact laws, social and economic rules and regulations so that everyone can bring maximum happiness to society while pursuing their own interests. The idea of utilitarianism has been inherited and further developed in the works of John Stuart Mill, Marshall, Francis Ysidro Edgeworth, and Henry Sidgwick. Later, inspired by Sidgwick, Pigou, the father of "welfare economics" applied utilitarianism as a natural basis to welfare economics in the early 20th century. Therefore, from this perspective, welfare economics originated from the utilitarian founder Bentham.

The third view is that some Western scholars believed that welfare economics originated from Hobson. J. A. Hobson (1858-1940) was an British bourgeois economists and reformists, and an early representative of welfare economics. He discussed welfare issues in a series of writings in the late 19th and early 20th centuries. Hobson believed that the central task of economics was to study how to promote human welfare, find out the principles underpinning wealth distribution under the current social system, and propose ways to improve the distribution of wealth to eliminate inequality in distribution. Hobson also proposed the concept of "organic welfare". He pointed out that welfare calculations were not based on individuals, but on the basis of society, that was, on the basis of "organic welfare". "Organic welfare" is the welfare expressed by the social utility that individuals need to combine with social needs. Although Hobson put forward some valuable opinions on welfare issues, he did not establish a system of welfare economics. The first theoretical system to establish welfare economics was Pigou, a famous economist at the University of Cambridge.

\subsection{Pigou's welfare economics}

In the $1820 \mathrm{~s}$, utilitarianism or utilityism became more and more popular under the influence of Bentham and Mill. Utilitarianism believed that the purpose of people's moral behavior should be the improvement of the individual's own welfare. When people act, they only consider his personal welfare. At the same time, the purpose of social behavior should be to maximize universal welfare, or it should be the greatest welfare for the most people. The old welfare economics was born on this philosophy.

Pigou inherited Marshall's point of view that"economics is a study of wealth, but also a study of scholars" and Marshall's cardinal utility theory and partial equilibrium theory, based on this, they are supplemented and developed to form a complete system of welfare economics. In his book Wealth and Welfare published in 1912, he first considered welfare economics as an independent subject. Subsequently, in the book Welfare Economics published in 1920, the system of welfare economics was established for the first time, which marked the official birth of welfare economics. Pigou thus received the title of "Father of Welfare Economics" in Western economics.

Pigou's welfare economics has two central topics: first, how to measure and promote social and economic welfare? He thus obtained the view of "equalization of income"; second, how can the optimal allocation of production resources be achieved? Through these two analyses, Pigou came to the conclusion that the government should intervene in the economy.

Pigou believed that welfare referred to a person's utility or satisfaction. The so-called social welfare is the sum of the social welfare of individual members. In social welfare, the portion of social welfare that can be measured directly or indirectly in money is called social and economic welfare. Pigou believed that the utility of different individuals could be added or subtracted to define the total social utility. The social goal is to achieve maximum happiness. Pigou used national income as a measure of economic welfare, which included the amount of national income and its distribution among members of society. Pigou believed that there were two criteria for examining social and economic welfare: the size of national income and the distribution of national income. 
Pigou believed that there were two ways to promote social and economic welfare: first, to optimize the allocation of production resources, so that the national income generated by the total amount of production resources reaches a maximum value. It is necessary to study how production resources are distributed among various economic sectors and how to make full use of the economic efficiency of production resources. The second is to make the distribution more even without reducing the national income. This is because, for individuals, the marginal utility of money is diminishing. Therefore, transferring a part of wealth from the rich to the poor will increase the social and economic benefits. In welfare economics, the optimal allocation of production resources is called the "efficiency" standard for testing social and economic benefits. The distribution of national income tends to be called the "fair" standard on average. On this basis, Pigou proposed two sufficient conditions to test whether economic welfare is improving. (1) If the national income increases and the distribution status does not "deteriorate", that is, the income of the poor does not decrease, the economic welfare will increase (efficiency conditions); (2) If the distribution status improves but the national income does not drop, then the economic welfare will increase (fair conditions).

How can we achieve optimal allocation of production resources? On the one hand, the benefits that an investment or an economic activity brings to individuals are different from the benefits to society. Pigou believed that the state should intervene in the economy in order to optimize the allocation of established production resources and thereby generate greater social and economic benefits. When an investment or an economic activity brings more benefits to the individual than to the community, the government should tax the private investor to curb this investment, and vice versa. On the other hand, in order to improve social and economic welfare by improving income distribution without reducing the national income, Pigou advocated progressive income tax and estate taxation, improving social and cultural education, and improving the health of workers and their children, and provide social security, social relief and other safeguards.

The welfare economics represented by Pigou is now called Old Welfare Economics, and it is corresponding to the new welfare economics. Compared with the new welfare economics, the old welfare economics has two major characteristics. First, the utility of the articles is measurable and additivity, the utility of different individuals is comparable - the cardinal utility theory. Second, it is considered that income distribution is equalized on the premise that the total national income does not change, and that the redistribution of income can increase social and economic benefits.

However, the old welfare economics also has some problems. The old welfare economics was based on the cardinal utility theory. Western economists at that time proposed the following objections: first, utility is a subjective feeling of a person, cannot be measured by a base, and cannot be used to add or subtract. Second, one's utility is incommensurable with another's utility. Interpersonal comparison is a value judgment or ethical judgment on a factual issue rather than an ordinary experience judgment. Third, there is no measurement unit for the base utility that applies to all people. In particular, the diminishing marginal utility of the currency means that the rich's currency should be transferred some to the poor. Western economists are the most taboo. These problems caused a great debate in the 1930s. The result of the debate was that the new welfare economics replaced the old welfare economics. Although the new welfare economics and Pigou's arguments are quite different, Pigou's propositions have become the focus of subsequent debates, so it has a great influence on the new welfare economics.

\subsection{Pareto welfare economics}

The new welfare economics was born in the 30s-40s of the 20th century, when Robins and others debated whether or not to conduct normative analysis and whether or not to add value judgments in economic analysis. Lionel. Robbins (1932) challenged the assumptions of interpersonal comparability and base utility measure in old welfare economics theory, questioned its scientificity and objectivity, and believed that welfare economics should be modified by applying ordinal information and incomparable information between people [8]. Robbins believed that the combination of economics and ethics was logically impossible, and economics should not involve 
issues of ethics or value judgments; the normative nature of economics came from the use of cardinal utility. He denied that the utility of individuals was comparable, so economics should avoid the use of cardinality. Robbins pointed out: "Any person's subjective world is difficult for others to understand, and the comparison of subjective feelings of different individuals does not exist." [9] For a detailed discussion, see Robbins (1935, pp. 138-140, pp. 149-150; 1938, pp. 636-637). Since then, Robbins $(1981$, p. 5) has reiterated his point: He does not oppose the "subjective" comparison of the utility of individuals. He believed that "subjectively" utility comparison among individuals cannot explain the correctness of the "objective" utility comparison between individuals.

Robbins' view soon became popular at the time. Soon, Hicks (1939) discovered from the original theory of Pareto $(1906,1913)$ the idea of enabling welfare economics to avoid the use of cardinality and restated it to become the Pareto standard that we are now familiar with, that is, the idea of comparing two kinds of social welfare. The introduction of the Pareto Standard concept has a profound influence on the development of the new welfare economics. The study of welfare economics in the subsequent three decades revolved around the expansion and development of the Pareto standard and Pareto optimality.

The most important significance of the Pareto standard introduction is the relationship between Pareto optimality and general equilibrium economy. On this basis, two basic theorems of welfare economics are proposed. The First Theorem of Welfare Economics: in a perfectly competitive economy, if there is a competitive equilibrium, then this equilibrium is Pareto optimal. The Second Theorem of Welfare Economics: if the economy is completely competitive, both the consumer utility function and the producer's production function are convex, the optimal Pareto resource allocation can be achieved through the market mechanism. The introduction of two basic theorems makes the system of welfare economics more perfect, making empirical analysis and normative analysis more deeply applied in welfare economics.

The defects of the Pareto standard are also obvious. The Pareto standard is too harsh on the two comparative economic conditions. In the actual economic life, there will always be some people who benefit from the implementation of any economic policy, and others will suffer damage. In this state, Due to the inability to compare, the Pareto criteria can only give a partial social ranking rather than a complete social order. The problem of Sen's Pareto freedom paradox clearly reveals the defects of the Pareto standard. The Pareto standard can only be an efficiency standard rather than a complete standard including the allocation problem. In order to solve the inherent limitations of the Pareto standard, some western economists have tried to supplement the Pareto standard. As a result, the "compensation standard school" and the "social welfare function school" emerged.

The "compensation standard school" is mainly represented by Kaldor (1939), Hicks (1940), Tibor, Scitovsky (1941), Samuelson (1950), and Litle (1957). According to John Chipman and James Moore, Enrico Barone proposed compensation principles as early as before Caldor and Hicks, "at least four times". Barone's groundbreaking contributions did not attract the attention of English-speaking economists. Even Von Hayek's translation of the Italian version into English version in 1935 did not draw attention. The school believes that in the actual social transformation, there are always some people who benefit while others are damaged. If social change must be conducted according to the Pareto-optimal principle, any realistic change is not desirable. This is actually negating any social change. The school believes that as long as the added benefits outweigh the reduced benefits, it can be assumed that such changes will increase social welfare. Johannes de V. Graff pointed out: "The compensation test was produced due to the requirements of how to evaluate social welfare..." [10]. The direct utility of the individual cannot be compared... The Pareto definition only compares the increase in benefits... but the supplementary test extends the situation to the situation where some people have reduced their benefits." However, there are serious logical contradictions in this school. Many economists such as William, Gorman (1955) believed that the lack of symmetry and transitivity of the Kaldor-Hicks compensation standard made the school of compensation less convincing. Therefore, the Kaldor standard, Hicks, and Sittovski standards all use efficiency as the only criterion for judgment. It not only failed to avoid the shortcomings of Pareto's standards, but also led to some inconsistencies in judgment. In contrast to the above criteria, 
Samuelson defined the principle of compensation in the form of a utility-possible boundary. This compensation principle can form transitive social welfare judgments, so there is no logical disadvantage. However, Samuelson's criteria were too harsh and produced conflicting social welfare judgments with Pareto criteria.

The core concept of the "social welfare function school" is the social welfare function. For the first time, the concept of social welfare function proposed by Abram, Bergson (1938) made an accurate description of social welfare standards. According to Chipman (1976) and Moore (1978), the Bergson-Samuelson social welfare function can be traced back to Pareto (1913). In fact, Pareto goes far beyond his time. In Pareto's early works, he examined the social welfare function with compassion. But it is fair to say that without the expansion of Bergson (1938) and Samuelson (1947, Chapter 8), the concept of social welfare function could not become the core concept of modern welfare economics. As Samuelson (1981, p. 248) wrote: "Only when you understand this problem clearly can you realize that Pareto has long perceive the confusion". According to this definition, welfare standards that guide social choice can be represented by a real-valued function; the real-valued function take the utility level of all members of society as independent variables, and this function is the social welfare function. Later, after the improvement of Samuelson (1947), it has now become the most important analytical tool for welfare economics. Inspired by Bergson, Arrow $(1951,1963)$ groundbreakingly introduced collective selection theory originated in the 18th century into the analysis of the basic problems of welfare economics, and successfully established an abstract model on the existence of social welfare standards. Although one of the basic ideas of systemic research and welfare economics on collective choice - utilitarianism or utilityism originated almost in the same era (Sen, 1999), for a long time, economists did not notice the significance of collective choice theory for welfare economics. However, Arrow's analytical framework still has its own limitations that cannot be ignored. These limitations determine that the conclusions that can be obtained under this framework will inevitably make the rational social choice improbable. Arrow's Impossibility Theorem makes the study of welfare economics into a period of perplexity. In order to thoroughly solve the basic problems, a group of modern welfare economists represented by Sen, in-depth analysis of the nature of collective choice and the limitations of Arrow's impossible theorem during the 30 years of the 1950s to the 1970s. Finally, a systematic solution was put forward, which made substantive development of welfare economics.

Through the discussion of the old welfare economics and the new welfare economics, we can see that the new welfare economics assumes that the ordinal utility and interpersonal utility are not comparable, and replaces the assumptions of the cardinality utility and the comparable interpersonal utility in the old welfare economics. Is this the progress or decline in the development of welfare economics theory? It requires us to conduct new research and discussion. The new welfare economics attempts to avoid the value judgment and to study welfare economics from an objective point of view, which has made welfare economics into a "dead end". This shows that the new welfare economics based on the Pareto standard also has insurmountable deficiencies. Therefore, the new welfare economics should properly introduce and draw lessons from the reasonable parts of the old welfare economics, such as the cardinal utility and interpersonal comparisons, so that in the framework of the new welfare economics can obtain a complete social welfare ranking, making the the study of welfare economics theoretically significant. Of course, the development of the theory can not be confined to the original system, but should relax the assumptions approaching reality. Welfarism, the cornerstone of welfare economics, regards utility as the only factor in social ordering. This hypothesis ignores other factors in real life, such as personal rights and freedoms, these defects led to the rise of non-welfareism later.

\subsection{Relative welfare theory}

The relative welfare doctrine was mainly developed after the 1960s. This theory was based on the theoretical assumption of relative income. The theory of relative income was proposed by J. S. Duesenberry (1949) in the book Theory of Income, Savings and Consumer Behavior [10]. He believes that a person's consumer spending is not only affected by his own income, but also by the 
surrounding people's consumer behavior and the relationship between their income and consumption. The main representatives of the relative income doctrine include E. J. Mishan, R. A. Easterlin, and others. Abramovitz published the article "Welfare Explanation of National Income and Long-Term Product Trends" in 1959, which was considered to be the earliest representative of relative welfare theory. This article expanded the discussion mainly through questioning Pigou's interpretation of welfare. He believed that there was no positive proportional relationship between the growth of social welfare and economic welfare and the growth of national income.

The economist who advocated relative welfare theory put forward the following propositions on the basis of Abramovici's arguments. First, according to the relative income hypothesis, the size of a person's welfare does not depend on his absolute income level. It depends on his relative income level, that is, it depends on the comparison with the income of others, especially the income of the members of the relationship group. The term "relationship group" was used in the book The Role of Human Action and Society edited by Ross in 1962 to explain consumer behavior. The so-called relationship group refers to those individuals who mentally connect with themselves. These people have similar preferences, habits, and lifestyles, and individual consumer behavior will be influenced by the group's evaluation criteria. Or, personal wishes and behaviors always strive to be similar to the members of the relationship group to which they belong. Second, Easterlin believed that welfare was equal to happiness. Happiness is a person's psychological feeling. It's different because of people, time and place, and the size of happiness is not necessarily related to the level of national income. Therefore, welfare has no scale to measure, nor can it be compared between people. Welfare varies from person to person, from place to place, and from time to time. Therefore, the comparison of the size of state-to-state welfare and the comparison of the size of welfare in different historical periods of the same country are meaningless. Only people who live in the same cultural context can compare welfare. On the other hand, we regard happiness as relative, which is through comparison. Third, since the increase in national income of a country does not indicate an increase in the welfare of the country, therefore, it is impossible to increase social welfare when the government imposes taxation (when the private marginal net output value is greater than the marginal social net output value) or allowances (when the marginal private net output value is less than the marginal social net output value). Fourth, because each nation's perception of welfare is inconsistent, the redistribution of national income (the distribution of the rich's income to the poor) does not increase social welfare. Because welfare is relative, the policy of eradicating poverty will only create new relative poor people. Therefore, welfare policy is of little significance. Fifth, human desires cannot be truly satisfied, and human desires are endless. The increase in income will only increase people's desires. There will be no change in welfare or happiness. Poverty cannot be eliminated. Therefore, relative welfare doctrine researchers believe that the implementation of various welfare policies is invalid. Sixth, relative welfare theory is pessimistic about the vision of future society. In other words, there is no basis for alleviating social conflicts through income redistribution and establishing an ideal future society.

\subsection{The expansion of welfare economics}

The expansion of welfare economics mainly stems from the defects of the new welfare economics. On the one hand, the basic theorem of welfare economics is perfect from the perspective of mathematical form, but these theoretical models have a big gap with the reality and need to be revised and improved. On the other hand, the Pareto criterion only focuses on efficiency issues, and neglects the issues of income distribution and equity. This led to Arrow's impossibility theorem, which made welfare economics stagnate. In order to make theoretical breakthroughs in welfare economics, economists have expanded welfare economics from the following aspects.

The first is the decision mechanism for social welfare standards. Social selection theory mainly studies how to draw social rankings based on personal rankings, which requires information on individual utility and interpersonal comparisons. This information can be divided into the following two points: first, the measurability of utility, including ordinal scale measurement, cardinal scale measurement, ratio scale measurement, absolute scale measurement, etc. Second, utility 
comparability, including incomparable, partially comparable, and fully comparable. Welfare economists have shown whether the utility is comparable or not and how it is comparability is the key condition for determining whether social ordering is possible. Therefore, the solution to social choice paradox, is mainly achieved through obtaining sufficient utility information. Whether to abandon the welfarist viewpoint or not is not the key to the problem.

The second is the expansion of basic theorems of welfare economics. The fundamental theorem of welfare economics is just a description of an ideal perfect competition or "invisible hand". It actually emphasizes the importance of the consistency of utility between individuals on the systems and beliefs of welfare economics and even of western economics as a whole. The establishment of the fundamental theorem requires the premise of a completely competitive market, which makes the economic state described in the basic theorem a vacuum. Because there are market failures in the real economy, market failures mainly include monopoly, externalities, public goods, and incomplete information. However, the existence of these market failures makes the utility between individuals conflicts, and thus cannot achieve the unity of efficiency and fairness under the theoretical framework of welfare economics. In addition to studying the basic forms of market failure, more and more attention is now being paid to the issues of mutual benefit, altruism, conscience effects among people, and etc.

The third is the suboptimal theory and the third superior theory. The Pareto standard and Pareto optimality are the core concepts of the new welfare economics. Pareto optimality is an efficient resource allocation model. Due to the existence of market failure, economic operation cannot achieve Pareto optimality. Moreover, in the real economy, a perfectly competitive market that can achieve Pareto optimality is impossible. That is, under the condition of constraints, we cannot achieve Pareto optimal position through policy adjustment. It is only possible to achieve a second-order Pareto-optimal maximum, ie, a suboptimal solution, under the constraints. Through further research of scholars, it has been found that due to government failure, information asymmetry, and the complexity of alternatives and complementarities between products, the goal of maximizing social welfare under restrictive conditions is also an illusion. That is, it is impossible to find sub optimal solutions under constraint conditions. The inability to find sub-optimal solutions causes the welfare economics theory to fall into a dilemma. This is the sub-optimal dilemma. In order to ease the sub-optimal dilemma, Yew-Kwang, $\mathrm{Ng}$ proposed the third superiority theory.

The fourth is the theory of fairness and justice. The relationship between fairness and efficiency has always been the focus of debate in welfare economics and even the entire economic community. The new welfare economists often need to rely on the results of philosophical research on this issue, because the discussion of fairness issues need to introduce value judgments. As Stevens later said, "Economists tend to bring them (economic efficiency standards and fairness standards - quoters note) together in a fairly crude way, because they have no special expertise or authority on these issues" [11]. The studies on the theory of fairness and justice conducted by welfare economists with the help of philosophy mainly include: first, the theory of fairness. The theory of fairness mainly includes the theory of fairness of equalitarianism distribution, the theory of fairness without envy, the theory of fairness of equalitarianism equivalent allocation, and the fairness theory of equitable equivalent allocation. Second, justice theory, which mainly includes utilitarian justice theory, rolson's justice theory, nozick's justice theory, Dworkin's justice theory, Sen and Nussbaum's justice theory and Marx's justice theory.

The fifth is inequality, poverty and famine. Empirical economic theory does not focus on inequality and poverty. It focuses only on the issue of free choice. Welfare economics, which belongs to normative theory, has made up for this deficiency. The main purpose of welfare economics lies in what policies will maximize social welfare. Therefore, the study of individual welfare and social welfare must pay attention to the real economic problems of inequality, poverty and famine.

\subsection{Non-welfarism}

The so-called welfarism or moral individualism means that the level of social welfare (determine 
social order or obtain social preference) depends only on the level of utility of the members of society or the individual's ranking and personal preferences. In welfare economics, personal utility (measured by cardinality or ordinal) is assumed to be the sole basis of judgment for social welfare and social choice. Sen pointed out in the book On Ethics and Economics that welfarism considered "the only intrinsic value standard for measuring and evaluating one thing is personal utility" [12]. To put it more precisely, welfarism has the following characteristics: first, everyone is the best judge of his own preferences. Personal preferences are assumed to satisfy reflexivity, completeness, and transitivity. Second, the possible value of social status is determined by the individual's perception of these states and the satisfaction they obtain. That is to say, judging the level of social welfare is based on the level of utility of the members of a society or the ordering of individuals and preferences of individuals, it is not necessary to consider the information of social members in other unrelated states. Third, there is no difference in Pareto. If everyone's preference for a certain two social statuses is indistinguishable, then there is no difference between the two states for the whole society. From the characteristics of welfarism, we can see that the only reasonable basis for evaluating social status is the information base for personal utility. Anything that personally considers unimportant will certainly not be evaluated by the entire society.

Bhaskar, Dutta pointed out in his introductory book The Economics of Welfare that "for two centuries, welfarism has been the dominant theme in welfare economics" [13]. The wealth of literature in welfare economics is also studied on the basis of welfarism. Welfareism assumes the premise of "rational economic man". It only judges behavior based on the results of selection, and the evaluation of behavior also considers only personal interests. This actually thinks that each person corresponds to a unique personal ranking. Each person's behavior is selected according to this order, and the sorting only depends on the individual's utility. Obviously, this hypothesis ignores other aspects of personal utility in real life, such as individual rights and personal freedom. Sen pointed out that "rational economic man" in welfarism was entirely a "rational fool".

Sen in 1982 in the book Selection, Welfare and Measurement pointed out that this simple economic man was practically a social idiot. Economic theory has always been filled with such rational fools, who are dressed in a single halo of preference ordering that can be applied to all situations [14]. Therefore, welfare economics should break through welfarism and include non-welfare issues such as individual rights and individual freedoms into its analytical framework.

Non-welfarism refers to determining the level of social welfare.In addition to judging the level of utility of the members of society or the ordering of individuals and personal preferences, it is also necessary to consider the issue of how social ordering occurs when there is conflict between these individual utilities or when there are disagreements. Some economists pointed out that nonwelfarism gradually replaced welfarism as the basic criterion of value judgment in welfare economics. The reason lies in the defects of arrow's impossibility theorem and Pareto's standard, and the reconsideration of efficiency and fairness. More importantly, welfarism advocates utility or welfare as the only indicator, and individuals only consider their own interests, which is irrational from the moral point of view. Therefore, how to correctly understand the utility or welfare, how to deal with personal interests and social public interests are the questions that welfare economics needs to continue to explore. The rise of non-welfareism provides a new idea for the discussion of this issue, which makes us re-examine the basic value judgment criteria of welfare economics.

Sen received the Nobel Prize in economics in 1998, on the one hand, it explains the theoretical contribution of Sen. On the other hand, it shows that non-welfareism has become an important part of the development of welfare economics as a whole, and has received widespread attention from the entire Western society. The key to the problem lies in how to apply the non-welfarism theory to welfare economics. The author believes that in the future, the new development of welfare economics will certainly have a more profound impact on the development of Western economics itself.

Of course, not all economists have advocated the introduction of non-welfareism in welfare economics, and the two economists, Sen and Yew-Kwang $\mathrm{Ng}$, began to argue. Sen believed that social ordering should use information other than utility information, and welfarism was not 
necessarily a basic value judgment; Yew-Kwang $\mathrm{Ng}$ believed that, under the assumption of complete information, welfarism was a basic value judgment, while individual rights and freedom were non-basic value judgments, and information outside of utility is considered because the information base of social choice is incomplete. From the arguments of the above two economists, it can be seen whether individual rights and individual freedom should be considered as an important factor in social welfare functions is different. The key to disagreement is whether welfareism is a basic value judgment.

\section{Summary}

At last of this paper, besides giving conclusion, we can analyze the limitations of the research and look forward to the future research directions.

\section{Acknowledgements}

Authors are grateful to Graduate Student Education Teaching Reform Project of Jiangsu Province (JGLX18-113); the Brand Major Construction Project of University in Jiangsu (PPZY2015B103); Teaching Reform Project of Jiangsu (2017JSJG047); Project of Evaluation Committee of Higher Education Society in Jiangsu (Pgwyh07101); Teaching Reform Project of Nanjing University of Finance and Economics (JGZ1701, JGZ1805).

\section{References}

[1] Pigou, A. C. 1920. The Economics of Welfare. 1st edn, London: Macmillan.

[2] Little, I. M. D. 1950. A critique of welfare economics. Oxford: Clarendon Press.

[3] Mishan, E. J. 1969b. Welfare Economics: Ten Introductory Essays. New York: Random House.

[4] Boadway, R. \& Bruce, N. 1984. Welfare Economics .Oxford: Basil Blackwell.

[5] Yew-Kwang Ng. 2004. Welfare Economics, Towards a More Complete Analysis. Palgrave Macmillan.

[6] Smith, A. 1776. An Inquiry Into the Nature and Causes of the Wealth of Nations. Edwin Cannan (ed). Chicago: University of Chicago Press.

[7] Bentham, J. 1789, 1907. An Introduction to the Principle of Morals and Legislation. Clstrnfon Press, Oxford.

[8] Robbins, Lionel. 1932. An Essay on the Nature and Significance of Economic Science. London: Macmillan.

[9] Robbins, Lionel. 1938. Interpersonal Comparisons of Utility: A Comment. Economic Journal. Vol. 48 Issue December, p. 635-641.

[10] Duesenberry, J. S. 1949. Income, Saving and the Theory of Consumer Behavior, Cambridge, Mass.: Harvard University Press.

[11] Stevens, J. B. 1999. The Economics of Collective Choice. 1st edn, Shanghai: Shanghai people's Publishing House.

[12] Sen, A. K. 1987a. On Ethics and Economics. Oxford: Basil Blackwell.

[13] Bhaskar Dutta. 1998. Welfare Economics. London: Oxford University Press.

[14] Sen, Amartya K. 1982. Choice, Welfare and Measurement. Basil Blackwell Publisher. 